\title{
The Interplay of Having an Abortion, Relationship Satisfaction, and Union Dissolution*
}

\author{
Kristin Hajek
}

\begin{abstract}
This study researches the associations between having an abortion, relationship satisfaction, and union dissolution. Empirical evidence on this topic is scarce, and there is a pronounced lack of studies analysing longitudinal data: Most previous studies have used data from women recruited from abortion clinics who are about to undergo an abortion, and therefore do not incorporate a prospective measure of relationship satisfaction pre-pregnancy. Panel studies, on the other hand, collect prospective data on various topics and allow for the estimation of more advanced models that can help identify causal mechanisms. Using data from the German Family Panel pairfam in combination with pooled logistic regressions, discrete-time event history models, as well as fixed effects regression models, this study compares relationships up to nine years before having had an abortion and eight years afterwards. The findings of the analyses can neither confirm that relationship satisfaction acts as a confounding factor that influences both the likelihood of terminating a pregnancy and union dissolution, nor as a mediating factor between having an abortion and union dissolution. A negative effect of having an abortion on relationship satisfaction appears to be only temporary. In the year of an abortion, relationship satisfaction decreases slightly. In the following years, a significant difference in relationship satisfaction to pre-abortion years is no longer visible. By using panel data, the temporal order of events can be retraced, resulting in the discovery that relationship satisfaction and union dissolution do not change drastically from pre-abortion values after having an abortion.
\end{abstract}

Keywords: Abortion · pairfam · Relationship satisfaction · Union dissolution

This article belongs to a special issue on "Identification of causal mechanisms in demographic research: The contribution of panel data". 


\section{Introduction}

Stressful life events can have an impact on relationship satisfaction and stability (Randall/Bodenmann 2009). For example, having children, relocating, and chronic illness can negatively influence partnership quality and even lead to union dissolution (Belsky et al. 1985; Boyle et al. 2008; Schmaling/Goldman Sher 2000). Research has shown that induced abortions (from now on "abortions") can be stressful for both the men and women involved (Kero/Lalos 2000). Having an abortion can thus be regarded as a stressful life event that might influence relationship satisfaction and union dissolution. On the other hand, relationship satisfaction can influence the decision to abort a pregnancy (Kero et al. 2001), with relationship problems ranking amongst the most often mentioned reasons for having an abortion (Biggs et al. 2013; Kirkman et al. 2009). A negative association between having an abortion and relationship satisfaction might therefore be explained by relationship satisfaction pre-pregnancy and not by a stressful abortion experience.

Only if the temporal order of events is considered can the causal mechanism be revealed. Cross-sectional data can compare the relationship satisfaction of couples who have had an abortion with couples who did not experience an abortion. However, this type of data cannot distinguish whether relationship satisfaction changed after having an abortion, or if couples terminated a pregnancy because they were less satisfied with their relationship. Therefore, longitudinal data is required, which not only can detect associations, but also help identify causal effects. Panel data enables an observation of individual changes following specific actions, events, or developments. By using panel data for this investigation, relationship satisfaction can be compared for the same individual before and after having an abortion, allowing for the detection of changes in relationship satisfaction in relation to having an abortion. Moreover, panel data permit the use of statistical models (such as fixed effects regression models) that control for all time-stable variation between couples who have reported having had an abortion and couples who haven't, allowing causal effects to be identified under weaker assumptions (Brüderl/Ludwig 2015).

The connection between having an abortion, stress, and mental health is a well-studied topic; however, few studies have addressed relationship satisfaction and stability after experiencing an abortion. Most studies addressing this topic haven't found any differences in sexual satisfaction or relationship quality between couples who report having had an abortion and those who haven't (Barnett et al. 1992; Freudenberg/Barnett 1988; Mauldon et al. 2015). However, some do find negative effects of abortion on relationships (e.g., Bianchi-Demicheli et al. 2001; Coleman et al. 2009), using either retrospective data or respondents recruited from abortion clinics (who are about to have an abortion). These data sources have the disadvantage that they do not incorporate an appropriate measure of pre-abortion relationship satisfaction. Longitudinal studies analysing the association between having an abortion and partnership characteristics are thus far very scarce, aside from one study by Väisänen (2017) that analyses register data. Unfortunately, these data do not contain a measure of relationship satisfaction. 
The German Family Panel pairfam, on the other hand, allows the comparison of relationship satisfaction and stability up to nine years before and eight years after a couple experiences an abortion. Having an induced abortion is illegal in Germany, but no legal recourse is taken in the first 12 weeks of gestation if a medical, criminological, or social indication is given and if the individual underwent obligatory consultation (according to $\S 218$ a of the German Criminal Code). Abortions after 12 weeks of gestation are only possible for medical reasons. The social stigma surrounding abortion is still present, and few women talk about their experiences (Busch 2015). In 2019, 100,893 abortions took place in Germany - a ratio of 57 to 10,000 women (Federal Statistical Office of Germany 2020). The number of abortions was 9 percent lower in 2019 than in 2009 (Federal Statistical Office of Germany 2020).

Using pairfam data, I am able to address this topic from different angles: It enables an analysis of factors that influence the likelihood of having an abortion, as well as partnership characteristics after a couple has experienced an abortion. First, I analyse the likelihood of having an abortion depending on relationship satisfaction. Second, I examine the risk of union dissolution for couples that have experienced an abortion. Third, relationship satisfaction after having an abortion is investigated. With this three-step approach, I aim to examine the complex association between relationship satisfaction, having an abortion, and union dissolution, as well as demonstrate the advantages of using panel data to detect causal mechanisms.

\section{Relationship satisfaction as a mediating or confounding factor}

The termination of a pregnancy can be defined as a (potentially) stressful life event, as it constitutes a demanding or even threatening situation perceived as stressful by most (Kero/Lalos 2000; Wheaton 1996). Individual stress can then expand to partnership stress: Bodenmann (2005) defined dyadic stress as a stressful event that affects both partners either directly (if both partners are faced with the same event) or indirectly (if the stress of one partner spills over to the other). An abortion can therefore constitute a dyadic stressor, as it can often be stressful for both partners. Even if one partner perceives an abortion as less stressful, the stress the other partner is confronted with might spill over. Dyadic coping strategies and cooperative use of common resources are expected to follow in order to minimize the stress felt (Bodenmann 2005). The consequences of dyadic stress on an intimate relationship depends on each partner's vulnerabilities and coping resources (Karney/Bradbury 1995). Poor adaptive processes, such as the inability to empathize or defensive problem-solving, may affect couples' communication and lead to partnership dissatisfaction or even dissolution (Randall/Bodenmann 2009). High relationship satisfaction, on the other hand, can lower the likelihood of union dissolution (Karney/Bradbury 1995; Lillard/Waite 1993). Hence, the stress of an abortion might lower relationship satisfaction and, consequently, lead to a higher likelihood of union dissolution. This logic implies that relationship satisfaction is a mediator between having an abortion and union dissolution, as shown in Figure 1. 
Fig. 1: Illustration of relationship satisfaction as a mediator between having an abortion and union dissolution

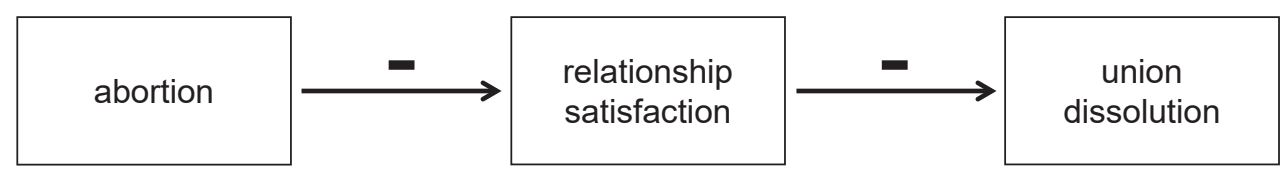

Source: Own design

On the other hand, the association between having an abortion and partnership characteristics might be explained by an opposite causal path. Some women worry that their relationship is too new or unstable to support a child without considerable strain (Kirkman et al. 2009; Mclntyre et al. 2001). Relationship satisfaction may influence the decision to abort a pregnancy (Kero et al. 2001), as partner-related issues are one of the main reasons given for having an abortion (Biggs et al. 2013). Partnership dissatisfaction pre-pregnancy might explain a positive association between having an abortion and partnership dissatisfaction and union dissolution after an abortion. Furthermore, it might be less likely to decide to become a parent if a separation seems likely in the near future, as separation costs are higher in the presence of a child (Lillard/Waite 1993). Thus, abortions might not cause union dissolutions, but might occur more frequently shortly before a separation. Figure 2 depicts relationship satisfaction as a confounder, with a negative effect on having an abortion as well as union dissolution. If this is indeed the case, a positive association between having an abortion and union dissolution might be explained by pre-abortion relationship dissatisfaction. In the following, several analyses are conducted in order to shed light on the complex association between relationship satisfaction, having an abortion, and union dissolution with the goal of identifying whether relationship satisfaction acts as a mediator or confounder.

Fig. 2: Illustration of relationship satisfaction as a confounder of having an abortion and union dissolution

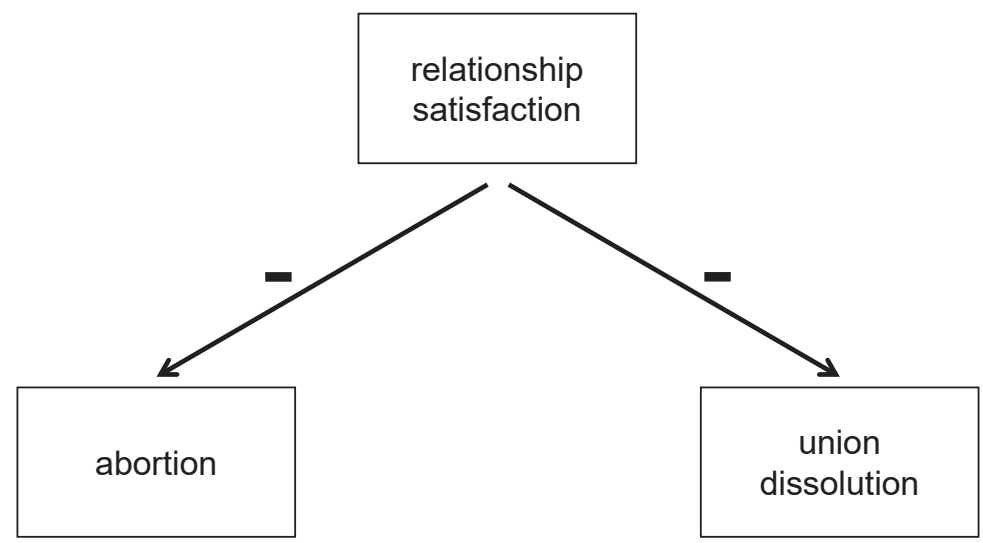

Source: Own design 


\section{Previous research}

Longitudinal analyses of Finnish register data reveal that experiencing a union dissolution is associated with a higher risk of abortion within the same year (Väisänen 2017). Register data offer a rich and reliable data source; however, relationship satisfaction is not reported. Therefore, the study cannot confirm whether relationship satisfaction is a confounder or a mediator in this relationship. Mauldon and colleagues (2015) used data from the Turnaway Study to compare women who had an abortion to women who were denied an abortion. Giving birth temporarily prolonged the latter group's current romantic relationship; however, just two years later, no differences were found between groups (Mauldon et al. 2015). Barnett and colleagues (1992) and Freudenberg and Barnett (1988) each recruited about 100 women from abortion clinics and questioned them a few days before having an abortion and one year later. Women in a stable partnership who reported using contraception were questioned as the control group. Some women indicated that the abortion experience resulted in their partnership dissolution (Barnett et al. 1992; Freudenberg/Barnett 1988). However, post hoc rationalisation might account for this finding since, objectively, no differences in union dissolution were found (Barnett et al. 1992). Separation often occurred more unexpectedly among the control group. Some women who had an abortion reported that the abortion experience served as an occasion to reflect on their relationship, realizing that the continuation was not desirable (Freudenberg/Barnett 1988).

Women in problematic relationships or who recently experienced a separation seem to be more likely to decide to have an abortion (Finer et al. 2005; Kirkman et al. 2009). Evidence on the effect of having an abortion on consequent relationship satisfaction seems to be rather thin. When retrospectively asked about their experience, most women don't report any effects of having an abortion on their relationship quality; however, some reported experiencing negative or positive changes in their relationship (Canario et al. 2011; Kero/Lalos 2005; Miller 1992; Miller et al. 1998). Philipps and colleagues only found one of four relationship quality items to differ between groups: women who reported having had an abortion (in the current or a past relationship) communicated less with their partners than women who never had an abortion (Phillips et al. 2015). Moreover, Coleman et al. (2009) found an increased risk of sexual dysfunction, arguments about finances, conflict over relatives, and jealousy among women who reported having an abortion with their current partner or in a previous relationship compared to women who never had an abortion. However, these two analyses do not distinguish whether the reported abortion happened in the current or a previous relationship. Therefore, effects of having an abortion in the current relationship can hardly be inferred. Barnett and colleagues (1992) and Freudenberg and Barnett (1988) detect more conflicts in the relationship shortly before having an abortion when compared to the control group. One year after the fact, no differences in relationship quality were detected.

So far, no known study has included an appropriate measure of relationship satisfaction pre-abortion. Some researchers that recruited respondents from abortion clinics questioned them a few days before the planned abortion (e.g. 
Bianchi-Demicheli et al. 2002; Freudenberg/Barnett 1988). However, evidence suggests that both men and women are more distressed in the days immediately preceding an abortion procedure compared to control groups. Women who have already decided to have an abortion experience elevated stress levels (Lauzon et al. 2000). Panel data, more specifically pairfam data, on the other hand, allow for a comparison of relationships several years before and after having had an abortion.

\section{Data and Variables}

pairfam is a multidisciplinary longitudinal study focusing on partnership and family dynamics in Germany. The partnership module encompasses questions regarding the development of intimate and sexual relationships and partnership quality and stability. Most questions are asked by an interviewer (Computer Assisted Personal Interview - CAPI), whereas sensitive questions regarding sexuality and abortion are included in a self-administered module (Computer Assisted Self Interview - CASI). Over 12,000 randomly sampled men and women from the birth cohorts 1991-93, 1981-83, and 1971-73 are surveyed annually. The first wave was conducted at the end of 2008/ beginning of 2009, at which point the first cohort was 15-17, the second 25-27, and the third 35-37 years old. Field work for the eleventh wave started in October 2018 and finished in August 2019. A more detailed description of the study can be found in Huinink et al. (2011). The subsequent analyses are based on anchor and partner data from waves 1-11, Release 11.0 (Brüderl et al. 2020a). The variables were measured as follows:

Abortion: From wave 2 onwards, female respondents were asked whether they had an abortion, and male respondents whether their female partner had an abortion since the last interview (or since the start of the relationship, if they reported having a new partner since the last wave). In 2019, 0.57 percent of German women had an abortion (Federal Statistical Office of Germany 2020). In the pairfam data, an average of 0.82 percent of women had an abortion in a single wave. However, pairfam observes respondents in their most fertile phase in life; a higher percentage of abortion occurrence is therefore plausible.

Union dissolution: Respondents indicate whether their relationship ended since the last wave, including up until which month it lasted.

Relationship satisfaction: Relationship satisfaction was measured on a scale from 0 to 10 (0: very dissatisfied - 10: very satisfied) in the pairfam data.

Control variables: Relationship duration, the number of living children, relationship institutionalisation (categories: non-cohabiting, cohabiting unmarried, married), the male partners' labour force status, the female partner's education level and age at the start of the relationship, and the gender of the main respondent can all influence relationship satisfaction, union dissolution, as well as the likelihood of having an abortion. Therefore, these variables are included as control variables in the subsequent analyses. In the following, several arguments as to why these variables can be considered confounders and therefore should be controlled for are discussed. 
Relationship duration: If a partnership is new, the likelihood of having an abortion (Kirkman et al. 2009; Väisänen 2017) as well as union dissolution (Brüderl/ Kalter 2001) is higher than in long-standing partnerships. However, relationship satisfaction is higher at the beginning of a relationship (Karney/Bradbury 1995). Relationship duration is measured in months, then divided by 12 to represent relationship duration in years (both linear and quadratic terms are included in the analyses).

Number of children: The number of children appears to positively influence the decision to abort (Broen et al. 2005; Kero et al. 2001). Having children reduces the risk of union dissolution (Brüderl 2000; Brüderl/Kalter 2001), although romantic partnerships without children report greater levels of relationship satisfaction compared to those with children (Meyer et al. 2016). The number of living children (categories: 0, 1, 2, 3 or more children) is therefore also included as a control variable.

Relationship institutionalisation: Unmarried partnerships are more inclined to both abort a pregnancy (Biggs et al. 2013; Rossier et al. 2007; Sihvo et al. 2003; Skjeldestad et al. 1994) and show higher levels of relationship dissatisfaction and breakups (Brown 2004; Poortman/Lyngstad 2007; Wiik et al. 2012) as compared to marriages.

Labour force status and education: Individuals in education or precarious working situations are more likely to have an abortion (Finer et al. 2005; Sihvo et al. 2003), while full-time employment of the male partner has a positive effect on relationship stability (Karney/Bradbury 1995; Killewald 2016). Women's employment status, on the other hand, is not related to relationship stability in Germany according to recent literature (e.g., Killewald 2016). Therefore, only male partner full-time and selfemployment, compared to part-time employment and unemployment, is controlled for. Women with a basic education have a higher likelihood of abortion (Väisänen 2015) and are more prone to relationship dissatisfaction and union dissolution (van Damme 2020; van Damme/Dykstra 2018) than women with higher levels of education. Therefore, this analysis distinguishes between "lower secondary education," "higher secondary education," "post-secondary/tertiary education," and "no degree/currently enrolled."

Female partner's age at start of relationship: The likelihood of union dissolution decreases with age at the start of a relationship (Brüderl 2000), and most women who report having had an abortion are between the ages of 20 and 29 (Jones/ Jerman 2017).

Gender (main respondent): The gender of the main respondent is controlled for as well, as men tend to report higher levels of marital satisfaction (Skolnick 1986). Moreover, men can only report abortions they are aware of.

Information on age at the start of the relationship, employment status, and education level were derived from generated variables provided by the pairfam project team, generated from the anchor respondent as well as the partner survey (Brüderl et al. 2020b). 


\section{$5 \quad$ Analysis of having an abortion}

\subsection{Sample description and methods}

First, I investigated the likelihood of having an abortion depending on relationship satisfaction. Do couples with different levels of relationship satisfaction have differing likelihoods of having an abortion? Most abortions are of unintended pregnancies (Henshaw 1998; Torres/Forrest 1988). The few women who abort planned pregnancies normally do so due to risks to their own health or foetal anomalies (Major et al. 2009). It is not recorded in the pairfam data whether the pregnancies of women who decide to have an abortion were planned or unplanned. However, less than four percent of abortions in Germany are due to health issues or foetal anomalies (Federal Statistical Office of Germany 2020). Therefore, it is assumed that the vast majority of the reported abortions in the pairfam data stem from unplanned pregnancies. As the circumstances of planned pregnancies are in many aspects vastly different to those that are unplanned, the reference group for the following analysis consists of unwanted/unexpected pregnancies that were carried to term. The analysis sample is defined as follows: Heterosexual couples who reported an abortion are compared to couples who experienced an unwanted/ unexpected pregnancy and decided not to terminate. In waves 2 and 3 , respondents who gave birth were asked whether the pregnancy was not wanted at all or whether the timing of the pregnancy was inconvenient. In the following waves, the question was formulated differently, asking whether the pregnancy was "unexpected." Births included in the analysis sample were therefore either unwanted (waves 2 and 3) or unexpected (waves 4-11).

A total of 2,116 planned births were excluded from the sample. Two observations indicating having had an abortion as well as given birth in the same year were omitted. Furthermore, 112 respondents without a partner and 3 respondents in homosexual partnerships have been excluded. The control variables of wave t-1 are merged with the indication of a birth or an abortion of the following wave $t$, and respondents who separate from their partners between these two waves were also excluded (50 cases). Unfortunately, the exact month an abortion took place is not collected in the pairfam data. As relationship satisfaction is the explanatory variable, it must be ensured that the decision to have an abortion happened in the context of a romantic relationship. Therefore, it is pivotal that the partnership did not end before the pregnancy occurred or before the female partner was aware of the pregnancy. After dropping 17 cases with missing values on the included variables, the final sample consists of 279 births and 254 abortions, for a total of 533 observations.

Table 1 lists the unweighted percentage of observations for the included categorical variables as well as mean values and standard deviations for metric variables. Mean relationship satisfaction for the analysis sample is 8.0 if the couple had an unexpected child and 7.6 if the couple decided to have an abortion. A t-test finds this difference to be statistically significant at the 5 percent level. In over 22 percent of all observations, respondents indicated that they are very satisfied 
Tab. 1: Descriptive statistics for the analysis of having an abortion

\begin{tabular}{|c|c|c|c|}
\hline \multirow[b]{2}{*}{ Variable } & \multicolumn{3}{|c|}{ Mean (SD) / Percent } \\
\hline & All & $\begin{array}{l}\text { Unexpected } \\
\text { childbirth }\end{array}$ & Abortion \\
\hline \multicolumn{4}{|l|}{ Metric variables: } \\
\hline Relationship satisfaction (scale: $0-10$ ) & $7.8(2.3)$ & $8.0(2.1)$ & $7.6(2.5)$ \\
\hline Relationship duration in years & $6.6(5.5)$ & $6.5(5.4)$ & $6.8(5.7)$ \\
\hline Female partner's age at start of relationship & $22.9(5.5)$ & $22.8(5.6)$ & $23.0(5.3)$ \\
\hline \multicolumn{4}{|l|}{ Categorical variables: } \\
\hline \multicolumn{4}{|l|}{ Number of living children } \\
\hline No children & 37.5 & 41.6 & 33.1 \\
\hline 1 child & 26.8 & 25.1 & 28.7 \\
\hline 2 children & 22.2 & 21.8 & 22.4 \\
\hline 3 or more children & 13.5 & 11.5 & 15.8 \\
\hline \multicolumn{4}{|l|}{ Relationship institutionalisation } \\
\hline Married & 50.5 & 50.9 & 50.0 \\
\hline Cohabiting, unmarried & 29.1 & 29.7 & 28.4 \\
\hline Non-cohabiting & 20.4 & 19.4 & 21.6 \\
\hline \multicolumn{4}{|l|}{ Female partner's education level } \\
\hline No degree/currently enrolled & 13.1 & 11.8 & 14.6 \\
\hline Lower secondary education & 13.7 & 12.2 & 15.4 \\
\hline Higher secondary education & 46.9 & 46.2 & 47.6 \\
\hline Post-secondary/tertiary education & 26.3 & 29.8 & 22.4 \\
\hline \multicolumn{4}{|l|}{ Male partner's employment status } \\
\hline Part-time/unemployed & 23.1 & 23.3 & 22.9 \\
\hline Full-time & 68.1 & 68.8 & 67.3 \\
\hline Self-employed & 8.8 & 7.9 & 9.8 \\
\hline Main respondent female (ref.: main respondent male) & 54.2 & 56.6 & 51.6 \\
\hline $\mathrm{N}$ (observations) & 533 & 279 & 254 \\
\hline $\mathrm{N}$ (couples) & 475 & 255 & 220 \\
\hline
\end{tabular}

Source: Author's calculations based on pairfam waves 1-11, Release 11.0

with their relationship. The mean relationship duration of the sample is between 6 and 7 years, while in about thirty percent of observations couples have been together for two years or less (158 observations).

For 90 percent of respondents, only one unwanted pregnancy or abortion was observed over eleven waves. For 10 percent of respondents, two or more observations are included in the following analysis. As within-panel analyses cannot be estimated, the following represents a cross-sectional analysis that compares relationships that experienced an abortion with relationships that experienced an unwanted/unexpected pregnancy that was carried to term. Pooled logistic regression models with lagged independent variables from the previous wave and cluster-robust standard errors are estimated. 


\subsection{Results}

Logistic regression analyses find a negative effect of relationship satisfaction on the likelihood of having an abortion (see average marginal effects in Model 1, Table A1 in the appendix). Figure 3 shows the predicted probabilities of having an abortion depending on relationship satisfaction with 95 percent confidence intervals, generated by the margins Stata command. Couples with a relationship satisfaction of 5 on a scale of 10 have a predicted abortion probability of 51 percent, while couples with a relationship satisfaction of 9 have a predicted abortion probability of 46 percent. However, this relationship is not significant at the 5 percent level.

Fig. 3: Conditional predicted probabilities of having an abortion depending on relationship satisfaction including 95 percent confidence intervals

Predicted probabilities of abortion

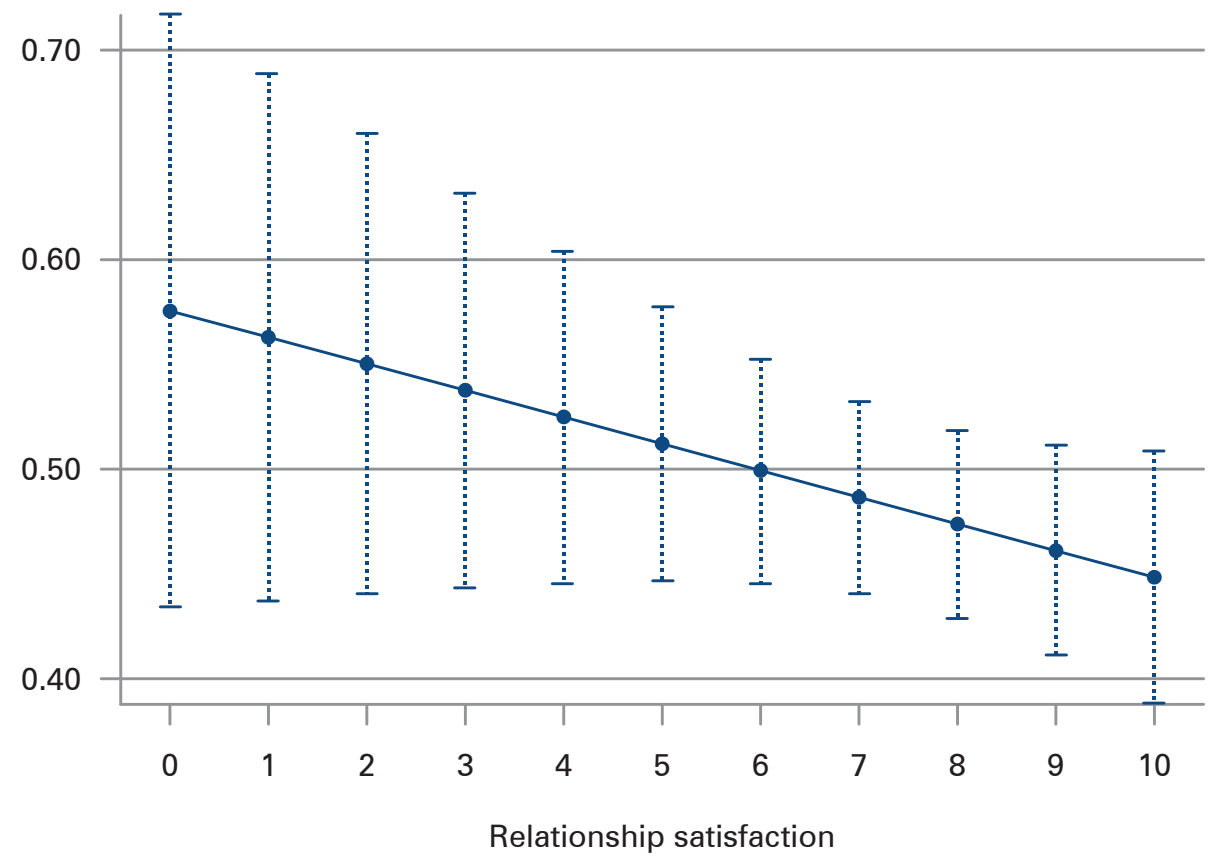

Notes: Based on logistic regression Model 1, Table A1. Controlling for relationship institutionalisation, number of living children, female partner's age at start of relationship and education level, male partners' employment status, and gender of main respondent.

Source: Own calculations based on pairfam waves 1-11, Release 11.0 


\section{Analysis of union dissolution}

\subsection{Sample description and methods}

To study the risk of union dissolution (separations and divorces) over relationship duration, a discrete-time event history model (Allison 1982; Singer/Willett 1993) is estimated. The survey waves define the discrete measurement points, and the main interest is the effect of the time-varying variable abortion on the risk of separation. Discrete-time event history models can be estimated in the same fashion as logistic regression models (Best/Wolf 2010). To account for duration dependency, a quadratic relationship duration term is included (Box-Steffensmeier/Jones 2004).

The dissolution of a union is recorded in wave $t$, although it happened between waves $\mathrm{t}-1$ and $\mathrm{t}$. In the case of a reported union dissolution, respondents are asked in which month it occurred. Similarly, if an abortion took place between waves t-1 and $t$ it is recorded in wave $t$. Unfortunately, the month in which an abortion occurred was not asked. Therefore, it is not known whether a separation reported in the same wave of having an abortion happened before or after the abortion. Nevertheless, it is assumed that it was the abortion that affected the dissolution (eventually by an anticipation effect), and not vice versa. Information on dissolution and abortion is copied to wave $t-1$, as information on the control variables was recorded the last time in wave t-1, before a dissolution occurred.

The unit of analysis is a romantic union. If a union lasted more than one wave, several observations of the same union are in the analysis sample. The analysis sample includes all unions in pairfam. If a respondent changes partners during the panel frame, this respondent can be part of the sample in different unions. The dependent variable dissolution is coded 1 if a dissolution occurred before the next wave and 0 if the union continued or if the union is censored (last observation in pairfam).

All men and women in heterosexual partnerships were included in the analysis. First, 21,549 observations of respondents without a partner and 452 observations of respondents in homosexual relationships were excluded. Next, 126 unions were deleted because their relationship started before they were 12 years old. To clearly distinguish between the effects of giving birth and having an abortion, 23 observations of couples who indicate that a child was born and that they also experienced an abortion in the same wave were removed. Then, 1,308 observations with missing values on any of the variables of interest were excluded. After eliminating 48 observations with identical values on the time variable (relationship duration) and 280 observations that began on or after the (first) separation (resulting from temporary breakups), the final sample includes 40,810 observations from 10,833 respondents. This sample includes 398 couples (with 1,300 observations) who report having, or their partner having had an abortion, and 318 couples (with 1,100 observations), that carried an unwanted/unexpected pregnancy to term. Almost eleven percent of observations in the final sample ended in separation.

To allow for a time-varying effect of abortion, four dummy variables were generated: wave of abortion (meaning: the interview was at most 12 months after 
abortion), one wave after abortion, two waves after abortion, and three or more waves after abortion. The variable wave of abortion is coded 1 if an abortion took place since the last wave, and 0 otherwise. The latter variables are coded 1 one/two/ three or more waves after an abortion was reported, respectively, and 0 otherwise.

The number of living children is a time-varying variable that increases by 1 if a child is born to the respective couple. In addition, four dummy variables indicating the waves after an unexpected/unwanted birth, constructed analogously to the dummy variables of having an abortion (wave of unexpected childbirth, one wave after unexpected childbirth, two waves after unexpected childbirth, and three or more waves after unexpected childbirth) are included.

Table 2 reports the unweighted percentage of observations for the included categorical variables as well as mean values and standard deviations for metric

Tab. 2: Descriptive statistics for the analysis of union dissolution

\begin{tabular}{|c|c|c|c|}
\hline \multirow[b]{2}{*}{ Variable } & \multicolumn{3}{|c|}{ Mean (SD) / Percent } \\
\hline & All & $\begin{array}{l}\text { Unexpected } \\
\text { childbirth }\end{array}$ & Abortion \\
\hline \multicolumn{4}{|l|}{ Metric variables: } \\
\hline Relationship satisfaction (scale: 0-10) & $7.9(2.2)$ & $7.6(2.2)$ & $7.3(2.4)$ \\
\hline Relationship duration in years & $9.0(7.3)$ & $8.2(6.1)$ & $8.2(7.0)$ \\
\hline Female partner's age at start of relationship & $22.7(6.1)$ & $22.9(5.6)$ & $23.9(6.0)$ \\
\hline \multicolumn{4}{|l|}{ Categorical variables: } \\
\hline \multicolumn{4}{|l|}{ Number of living children } \\
\hline No children & 41.3 & 11.2 & 28.9 \\
\hline 1 child & 20.3 & 31.8 & 27.4 \\
\hline 2 children & 26.2 & 28.6 & 25.2 \\
\hline 3 or more children & 12.2 & 28.4 & 18.5 \\
\hline \multicolumn{4}{|l|}{ Relationship institutionalisation } \\
\hline Married & 51.9 & 57.7 & 50.1 \\
\hline Cohabiting, unmarried & 23.4 & 30.9 & 27.8 \\
\hline Non-cohabiting & 24.7 & 11.4 & 22.1 \\
\hline \multicolumn{4}{|l|}{ Female partner's education level } \\
\hline No degree/currently enrolled & 17.3 & 8.7 & 13.2 \\
\hline Lower secondary education & 6.3 & 15.3 & 14.4 \\
\hline Higher secondary education & 48.7 & 48.8 & 49.0 \\
\hline Post-secondary/tertiary education & 27.7 & 27.2 & 23.4 \\
\hline \multicolumn{4}{|l|}{ Male partner's employment status } \\
\hline Part-time/unemployed & 25.8 & 20.2 & 23.5 \\
\hline Full-time & 66.4 & 71.2 & 67.0 \\
\hline Self-employed & 7.8 & 8.6 & 9.5 \\
\hline Main respondent female (ref.: main respondent male) & 57.9 & 59.5 & 56.6 \\
\hline $\mathrm{N}$ (observations) & 40,810 & 1,100 & 1,300 \\
\hline $\mathrm{N}$ (couples) & 10,833 & 318 & 398 \\
\hline
\end{tabular}

Source: Own calculations based on pairfam waves 1-11, Release 11.0 
variables. Relationship duration is lower for observations of couples that decided to terminate a pregnancy. Furthermore, they were older at the start of the relationship and more often are in unmarried relationships.

\subsection{Results}

The average marginal effects estimated by the event history models are presented in Table A2 in the appendix. Both models control for relationship duration, relationship institutionalisation, the number of living children, the female partner's education level and age at start of relationship, the male partners' employment status, and the gender of the main respondent. No significant effect on union dissolution is visible after having an abortion. Additionally, Model 3 controls for relationship satisfaction, which has a strong effect on union dissolution: The higher the respondent's relationship satisfaction, the lower the risk of union dissolution. However, the effect of having an abortion on union dissolution decreases only slightly (see Model 3, Table A2). Figure 4 depicts the predicted probabilities of union dissolution over relationship duration from Model 2 generated through the margins Stata command. The reference group is comprised of all heterosexual couples who did not experience an abortion or an unwanted/unexpected childbirth (blue line). These observations show a reduction in predicted probabilities of union dissolution with an increase in relationship duration that are in line with recent research (Jalovaara/Kulu 2018). Furthermore, Figure 4 depicts predicted probabilities of union dissolution for couples that experience an abortion in the second year of their relationship (red line) and couples that experience an unwanted/unexpected birth in the second year of their relationship (green line). In the wave of abortion, the predicted probability of union dissolution decreases slightly. In the following two waves, the likelihood of separation increases; thereafter, probabilities realign with the reference group. However, the effects are rather small and not significant. Giving birth to an unexpected/unwanted child, on the other hand, decreases the likelihood for union dissolution significantly in the first two waves. Afterwards, predicted probabilities realign. Introducing a third-order time variable as well as including the logarithm of relationship duration yielded similar results to those presented.

\section{Analysis of relationship satisfaction}

\subsection{Sample description and methods}

Next, I examined relationship satisfaction after having an abortion. Again, all heterosexual partnerships were included in the analysis sample. Control variables from one wave were merged with the indication of an abortion and relationship satisfaction from the next wave. First, 21,290 observations of respondents without a partner and 4,844 observations with a change in partner between the merged waves were excluded. Second, 363 observations of respondents in homosexual relationships were deleted and 113 unions eliminated because their relationship 
Fig. 4: $\quad$ Conditional predicted probabilities of union dissolution depending on relationship duration

Predicted probabilities of union dissolution

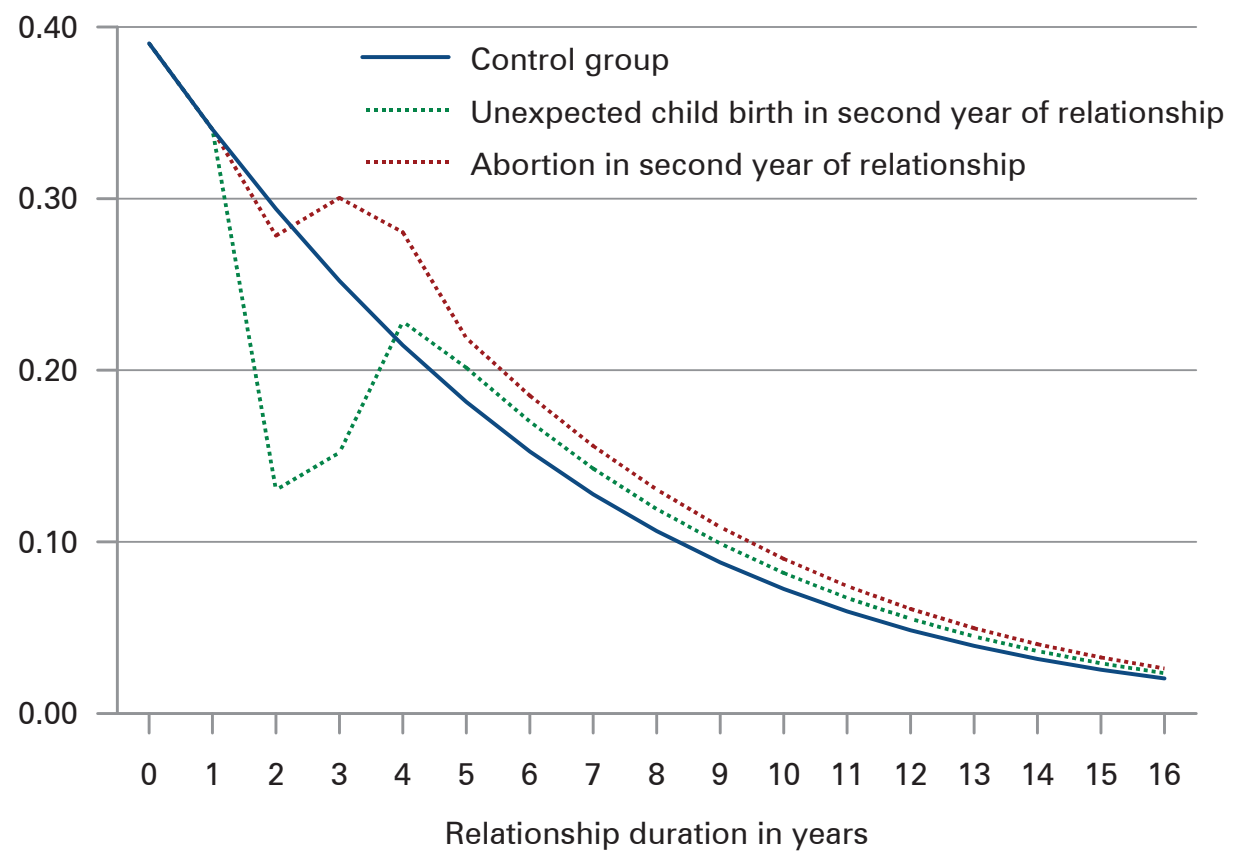

Notes: Based on discrete-time event history Model 2, Table A2. Controlling for relationship institutionalisation, number of living children, female partner's education level and age at start of relationship, male partner's employment status, and gender of main respondent.

Source: Own calculations based on pairfam waves 1-11, Release 11.0

started before they were 12 years old. Furthermore, 21 observations of couples who had an abortion and also reported the birth of a child in the same wave were removed. Then, 1,245 observations with missing values on any of the included variables were dropped. Next, only couples who did not have an abortion or unexpected birth in the first wave of panel participation were included in order to have a baseline measurement of relationship satisfaction (592 observations dropped). Moreover, in order to conduct a panel analysis, respondents with less than two observations were excluded (2,272 observations). The final sample consists of 32,683 observations from 5,901 couples, 140 of which who reported having an abortion (935 observations) and 202 of which who reported having an unexpected/ unwanted birth (781 observations).

Again, four dummy variables were generated to indicate the effect of having an abortion over time: wave of abortion (meaning: the interview took place at most 12 months after the abortion), one wave after abortion, two waves after abortion, and three or more waves after abortion. A summary of the variables used for the 
following analysis is presented in Table 3 (all couples versus couples that experienced an abortion). The first column shows the unweighted percentage of observations for dichotomous variables, and mean values with standard deviation in brackets for metric variables. The second column indicates the unweighted percentage of respondents who changed their status regarding each variable between waves. Relationship satisfaction is slightly lower if the couple experienced an abortion (7.3 vs. 7.8) and relationship satisfaction of 93.6 percent of couples who experienced an abortion ever changed between waves.

First, a pooled linear regression model (POLS) was conducted, followed by an estimation with fixed effects (FE) regression models with cluster-robust standard

Tab. 3: Descriptive statistics for the analysis of relationship satisfaction

\begin{tabular}{|c|c|c|c|c|}
\hline \multirow[b]{2}{*}{ Variable } & \multicolumn{2}{|c|}{ All } & \multicolumn{2}{|c|}{ Abortion } \\
\hline & $\begin{array}{c}\text { Mean (SD) / } \\
\text { Percent }\end{array}$ & $\begin{array}{l}\text { Percent of } \\
\text { couples with } \\
\text { change } \\
\text { between } \\
\text { waves }\end{array}$ & $\begin{array}{l}\text { Mean (SD) / } \\
\text { Percent }\end{array}$ & $\begin{array}{c}\text { Percent of } \\
\text { couples with } \\
\text { change } \\
\text { between } \\
\text { waves }\end{array}$ \\
\hline \multicolumn{5}{|l|}{ Metric variables: } \\
\hline \multicolumn{5}{|l|}{ Relationship satisfaction } \\
\hline Relationship duration in years & $10.1(7.2)$ & 100.0 & $8.9(5.9)$ & 100.0 \\
\hline \multicolumn{5}{|l|}{ Categorical variables: } \\
\hline \multicolumn{5}{|l|}{ Number of living children } \\
\hline No children & 35.7 & 14.3 & 25.3 & 27.9 \\
\hline 1 child & 21.6 & 21.3 & 25.4 & 39.3 \\
\hline 2 children & 29.1 & 17.1 & 30.5 & 34.3 \\
\hline 3 or more children & 13.6 & 5.8 & 18.8 & 16.4 \\
\hline \multicolumn{5}{|l|}{ Relationship institutionalisation } \\
\hline Married & 59.0 & 16.5 & 60.3 & 27.9 \\
\hline Cohabiting, unmarried & 23.9 & 28.8 & 29.1 & 42.1 \\
\hline Non-cohabiting & 17.1 & 21.0 & 10.6 & 30.0 \\
\hline \multicolumn{5}{|l|}{ Female partner's education level } \\
\hline No degree/currently enrolled & 12.5 & 13.1 & 8.6 & 10.7 \\
\hline Lower secondary education & 5.8 & 3.1 & 10.6 & 5.7 \\
\hline Higher secondary education & 50.8 & 10.8 & 49.4 & 10.7 \\
\hline Post-secondary/tertiary education & 30.9 & 6.2 & 31.4 & 7.9 \\
\hline \multicolumn{5}{|l|}{ Male partner's employment status } \\
\hline Part-time/unemployed & 20.7 & 25.4 & 17.3 & 32.1 \\
\hline Full-time & 70.9 & 29.7 & 69.2 & 39.3 \\
\hline Self-employed & 8.4 & 8.8 & 13.5 & 15.0 \\
\hline N (observations) & 32,683 & 32,683 & 935 & 935 \\
\hline N (couples) & 5,901 & 5,901 & 140 & 140 \\
\hline
\end{tabular}

Source: Own calculations based on pairfam waves 1-11, Release 11.0 
errors. Compared to pooled regression models, results of the FE models can be based on a within-person comparison while controlling for time-constant variables (Brüderl/Ludwig 2015). Therefore, the time-stable control variables female partner's age at start of relationship and gender of main respondent need not to be included in the model as they are automatically controlled for. Unobserved heterogeneity caused by time-constant variables does not bias the estimation, as only information on intra-individual changes over time is used and need not be accounted for in the model (Wooldridge 2010). In FE models, only respondents that reported experiencing an abortion are relevant to the estimation of the effect of having an abortion on relationship satisfaction. However, the control group remains in the analysis sample in order to provide reliable estimations for the control variables.

\subsection{Results}

Table A3 in the appendix presents the main coefficients from POLS and FE regression models predicting levels of relationship satisfaction. The pooled linear regression shows a statistically significant decrease of roughly 0.5 to 0.7 points in relationship satisfaction in the waves following an abortion (Model 4). In the fixed effects model, the effect is considerably smaller (see Table A3, Model 5). Figure 5 shows the change in relationship satisfaction after having an abortion including 95 percent confidence intervals as estimated by the FE model (Model 5). Immediately after an abortion, relationship satisfaction decreases 0.3 points, just reaching significance at the 5 percent level. In the next two waves, the effect is almost zero. Three or more waves after having an abortion the effect is again larger, but not statistically significant.

Either couples' satisfaction rises again one wave after having an abortion, or less satisfied couples separate and are not observed a second time after having an abortion. Bivariate analyses reveal that about 66 percent of couples whose relationship satisfaction is lower in the wave of an abortion are interviewed at least once more, while 75 percent of couples whose relationship satisfaction is the same or increased in the wave of abortion are interviewed at least one more time. Therefore, the alignment in relationship satisfaction one wave after abortion may be partly due to less satisfied relationships separating. However, the 66 percent of couples that have been interviewed a second time after having an abortion show, on average, a rise in relationship satisfaction after the initial drop in the wave of the abortion. Thus, it seems that the vanishing effect of an abortion on relationship satisfaction is not solely due to selection by union dissolution.

\section{Discussion}

This study sought to investigate the association between relationship satisfaction, experiencing an abortion, and union dissolution. The experience of an abortion can be regarded as a stressful life event that could potentially lead to partnership dissatisfaction and union dissolution. However, relationship satisfaction could also 
Fig. 5: Change in relationship satisfaction after having an abortion including 95 percent confidence intervals

Change in relationship satisfaction

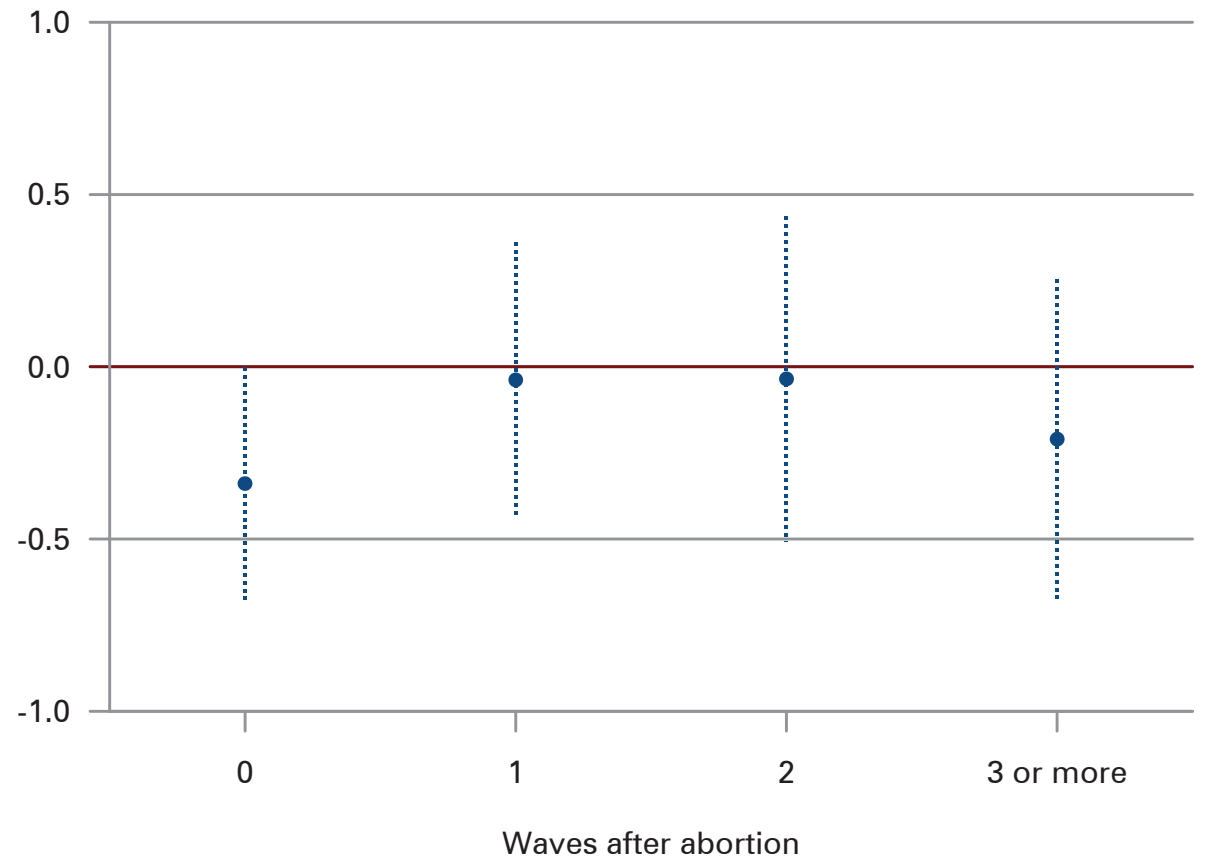

Notes: Based on linear fixed effects panel regression Model 5, Table A3. Controlling for relationship duration, relationship institutionalisation, number of living children, female partner's education level, and male partner's employment status.

Source: Own calculations based on pairfam waves 1-11, Release 11.0

be a confounding factor, influencing both union dissolution and the likelihood of having an abortion. Few studies have addressed this association and no measure of relationship satisfaction pre-pregnancy has thus far been included in analyses. Using data from the German Family Panel pairfam, I was able to compare relationship satisfaction several years pre- and post-abortion to more accurately examine its interplay with union dissolution. The chosen panel data allow for the consideration of the temporal order of events, which helps identify causal mechanisms and sheds light on the associations between relationship satisfaction, having an abortion and union dissolution.

Results show a higher likelihood to abort a pregnancy with lower relationship satisfaction which is in line with previous research (Kero et al. 2001; Biggs et al. 2013). Couples that are more satisfied with their relationship are less likely to experience an abortion. However, the effect is not significant at the 5 percent level. The likelihood of union dissolution is slightly higher after an abortion was recorded compared to couples who neither experienced an abortion nor an unwanted/ 
unexpected birth (statistically not significant). This supports previous research that found no significant impact of having an abortion on separation rates (e.g., Barnett et al. 1992). Carrying an unwanted/unexpected pregnancy to term, on the other hand, seems to decrease the likelihood for union dissolution in the following two waves, which explains why previous studies found higher separation rates for couples who had an abortion compared to couples who carried an unwanted pregnancy to term (e.g., Mauldon et al. 2015).

After having an abortion, relationship satisfaction decreases slightly, but only in the wave the abortion took place. In the following waves, no lasting effect of having an abortion on relationship satisfaction is visible. Furthermore, the effect on relationship satisfaction is smaller in the fixed effects models compared to pooled regression models, suggesting that couples who experience an abortion differ in their pre-pregnancy relationship satisfaction or other unobserved indicators from couples who do not terminate their unwanted pregnancy.

Therefore, these results can neither confirm that relationship satisfaction acts as a confounding factor that influences both the likelihood of terminating a pregnancy and union dissolution, nor as a mediating factor between having an abortion and union dissolution. The effect of relationship satisfaction on the likelihood of having an abortion is not significant. Moreover, the negative effects on relationship satisfaction appear to be only temporary and the increase in probabilities for union dissolution after having an abortion is so small that it is not statistically significant. These results are therefore in line with studies that found no major effects of having an abortion on relationship quality (e.g., Barnett et al. 1992; Kero/Lalos 2005; Miller 1992).

The study also has some limitations:

1) Abortion is still a taboo topic in Germany (Busch 2015), which might lead to underreporting. The pairfam data shows a higher prevalence of abortion compared to German Abortion Statistics (Federal Statistical Office of Germany 2020); however, this might be due to pairfam's young sample.

2) The stress of having an abortion might also lead to panel attrition or union dissolution. Changes in relationship satisfaction can only be analysed if the couple is still together in the wave following an abortion. Immediate breakups after having an abortion might not be included in the analysis. However, the event-history analysis found no association between having an abortion and union dissolution in the wave an abortion was reported. Therefore, those couples were still integrated in the analysis on relationship satisfaction in the wave of abortion. In the following waves, the effect of having an abortion on union dissolution was positive, but not statistically significant. Furthermore, 66 percent of respondents who reported a decrease in relationship satisfaction in the wave of an abortion are interviewed at least once more. For these respondents, no lasting change in relationship satisfaction was observed in the following waves.

3) Unfortunately, no indication was given in pairfam data whether the couple agreed on the decision of whether or not to terminate the pregnancy. A disagreement at this stage might also have consequences on relationship satisfaction and union dissolution. 
4) Furthermore, depending on the analysis, only 140 to 398 couples (with 2541,300 observations) that experienced an abortion were able to be included in the models. These results must therefore be interpreted with care. Future research should strive to replicate these results with more observations and analyse whether couples who agree on the decision to have a child or an abortion differ from couples who disagree.

\section{Conclusion}

By using data from the German Family Panel pairfam, a more accurate temporal order in which the events surrounding an abortion unfold could be established. Separate regression models for each step could be estimated and the association between the three main variables relationship satisfaction, having an abortion and union dissolution could be tested while controlling for confounding variables. This approach can help to identify causal mechanisms behind this association and examine whether relationship satisfaction changes after having an abortion, leading to union dissolution, or whether couples have an abortion and separate because they are less satisfied with their relationship.

Results support neither hypothesis. Neither relationship satisfaction before having an abortion nor union dissolution after having an abortion are significantly different from the control group. The only statistically significant effect is found for relationship satisfaction after having an abortion: Couples who experienced an abortion also experience a temporary drop in relationship satisfaction. The cause of this decrease in relationship satisfaction is not certain - it could be attributed to the abortion itself, or also to problems arising from the social stigma surrounding abortion, or even to the disagreement on whether to terminate the pregnancy. Data on whether the couples agree on the decision to have a child, attitudes towards having an abortion, and the perceived social stigma of having an abortion would help to identify the mechanisms behind this temporary decrease in relationship satisfaction. However, relationship satisfaction and union dissolution do not seem to change drastically from pre-abortion values after having an abortion.

\section{Acknowledgements}

My thanks go to Prof. Dr. Josef Brüderl and Prof. Dr. Johannes Huinink for editing this Special Issue and for their invaluable input. Special thanks go to Dr. Gerrit Bauer for his insights and statistical advice. Furthermore, I would like to thank Dr. Christiane Bozoyan, Christoph Erkunt, Dr. Claudia Schmiedeberg, Nina Schumann, and Philipp Schütze for their helpful feedback, Madison Garrett for language editing, as well as the two anonymous referees for their constructive comments. This study uses data from the German Family Panel pairfam, coordinated by Josef Brüderl, Sonja Drobnič, Karsten Hank, Johannes Huinink, Bernahrd Nauck, Franz Neyer, and Sabine Walper. pairfam is funded as long-term project by the German Research Foundation (DFG). 


\section{References}

Allison, Paul D. 1982: Discrete-time methods for the analysis of event histories. In: Sociological Methodology 13: 61-98. https://doi.org/10.2307/270718

Barnett, Winfried; Freudenberg, Nahid; Wille, Reinhard 1992: Partnership after induced abortion: A prospective controlled study. In: Archives of Sexual Behavior 21,5: 443455. https://doi.org/10.1007/BF01542269

Belsky, Jay; Lang, Mary E.; Rovine, Michael 1985: Stability and change in marriage across the transition to parenthood: A second study. In: Journal of Marriage and the Family 47,4: 855-865. https://doi.org/10.2307/352329

Best, Henning; Wolf, Christof 2010: Logistische Regression. In: Wolf, Christof; Best, Henning (Eds.): Handbuch der sozialwissenschaftlichen Datenanalyse. Wiesbaden: VS Verlag für Sozialwissenschaften: 827-854. https://doi.org/10.1007/978-3-531-92038-2_31

Bianchi-Demicheli, Francesco et al. 2001: Contraception and sexuality after termination of pregnancy: A comparison between Lugano and Geneva. In: Swiss Medical Weekly 131,35-36: 515-520.

Bianchi-Demicheli, Francesco et al. 2002: Termination of pregnancy and women's sexuality. In: Gynecologic and Obstetric Investigation 53,1: 48-53. https://doi.org/10.1159/000049411

Biggs, M. Antonia; Gould, Heather; Foster, Diana Greene 2013: Understanding why women seek abortions in the US. In: BMC Women's Health 13;29. 1-13. https://doi.org/10.1186/1472-6874-13-29

Bodenmann, Guy 2005: Dyadic coping and its significant for marital functioning. In: Revenson, Tracey A.; Kayser, Karen; Bodenmann, Guy (Eds.): Couples Coping with Stress: Emerging Perspectives on Dyadic Coping. Washington, D.C.: American Psychological Association: 33-50. https://doi.org/10.1037/11031-002

Box-Steffensmeier, Janet M.; Jones, Bradford S. 2004: Event History Modeling. A Guide for Social Scientists. Cambridge, MA: Cambridge University Press.

Boyle, Paul J. et al. 2008: Moving and union dissolution. In: Demography 45,1: 209-222. https://doi.org/10.1353/dem.2008.0000

Broen, Anne Nordal et al. 2005: Reasons for induced abortion and their relation to women's emotional distress: A prospective, two-year follow-up study. In: General Hospital Psychiatry 27,1: 36-43. https://doi.org/10.1016/j.genhosppsych.2004.09.009

Brown, Susan L. 2004: Moving from cohabitation to marriage: Effects on relationship quality. In: Social Science Research 33,1: 1-19. https://doi.org/10.1016/S0049-089X(03)00036-X

Brüderl, Josef 2000: The dissolution of matches: Theoretical and empirical investigations. In: Weesie, Jeroen; Raub, Werner(Eds.): The Management of Durable Relations. Amsterdam: Thela Thesis: 129-130.

Brüderl, Josef et al. 2020a: The German Family Panel (pairfam). GESIS Data Archive. Cologne. ZA5678 Data file Version 11.0.0. https://doi.org/10.4232/pairfam.5678.11.0.0

Brüderl, Josef et al. 2020b: pairfam Data Manual, Release 11.0. LMU Munich: Technical report. GESIS Data Archive. Cologne. ZA5678 Data file Version 11.0.0. https://doi.org/10.4232/pairfam.5678.11.0.0

Brüderl, Josef; Kalter, Frank 2001: The dissolution of marriages: The role of information and marital-specific capital. In: The Journal of Mathematical Sociology 25,4: 403-421. https://doi.org/10.1080/0022250X.2001.9990262 
Brüderl, Josef; Ludwig, Volker 2015: Fixed-effects panel regression. In: Best, Henning; Wolf, Christof (Eds.): The SAGE Handbook of Regression Analysis and Causal Inference. London: Sage: 327-357.

Busch, Ulrike 2015: Vom individuellen und gesellschaftlichen Umgang mit dem Thema Abtreibung. In: Busch, Ulrike; Hahn, Daphne (Eds.): Abtreibung. Diskurse und Tendenzen. Bielefeld: Transcript: 1-40.

Canario, Catarina; Figueiredo, Bárbara; Ricou, Miguel 2011: Women and men's psychological adjustment after abortion: A six months prospective pilot study. In: Journal of Reproductive and Infant Psychology 29,3: 262-275. https://doi.org/10.1080/02646838.2011.592974

Coleman, Priscilla K.; Rue, Vincent M.; Coyle, Catherine T. 2009: Induced abortion and intimate relationship quality in the Chicago Health and Social Life Survey. In: Public Health 123,4: 331-338. https://doi.org/10.1016/j.puhe.2009.01.005

Federal Statistical Office of Germany 2020: Press release number 070 [https://www. destatis.de/DE/Presse/Pressemitteilungen/2020/03/PD20_070_233.html, 15.02.2021].

Finer, Lawrence B. et al. 2005: Reasons U.S. women have abortions: Quantitative and qualitative perspectives. In: Perspectives on Sexual and Reproductive Health 37,3: 110-118.

Freudenberg, Nahid; Barnett, Winfried 1988: Partnerschaften nach Notlagen-Abruptio - Eine longitudinale Vergleichsstudie. In: Fortschritte der Neurologie Psychiatrie 56,9: 300-308. https://doi.org/10.1055/s-2007-1001794

Henshaw, Stanley K. 1998: Unintended pregnancy in the United States. In: Family Planning Perspectives 30: 24-29, 46

Huinink, Johannes et al. 2011: Panel analysis of intimate relationships and family dynamics (pairfam): Conceptual framework and design. In: Journal of Family Research 23,1: 77-101.

Jalovaara, Marika; Kulu, Hill 2018: Separation risk over union duration: An immediate itch? In: European Sociological Review 34,5: 486-500. https://doi.org/10.1093/esr/jcy017

Jones, Rachel K.; Jerman, Jenna 2017: Population group abortion rates and lifetime incidence of abortion: United States, 2008-2014. In: American Journal of Public Health 107,12: 1904-1909. https://doi.org/10.2105/AJPH.2017.304042

Karney, Benjamin R.; Bradbury, Thomas N. 1995: The longitudinal course of marital quality and stability: A review of theory, method, and research. In: Psychological Bulletin 118,1. 3-34. https://doi.org/10.1037/0033-2909.118.1.3

Kero, Anneli et al. 2001: Legal abortion: A painful necessity. In: Social Science \& Medicine 53,11: 1481-1490. https://doi.org/10.1016/S0277-9536(00)00436-6

Kero, Anneli; Lalos, Ann 2000: Ambivalence - A logical response to legal abortion: A prospective study among women and men. In: Journal of Psychosomatic Obstetrics \& Gynecology 21,2: 81-91. https://doi.org/10.3109/01674820009075613

Kero, Anneli; Lalos, Ann 2005: Increased contraceptive use one year post-abortion. In: Human Reproduction 20,11: 3085-3090. https://doi.org/10.1093/humrep/dei187

Killewald, Alexandra 2016: Money, work, and marital stability: Assessing change in the gendered determinants of divorce. In: American Sociological Review 81,4: 696-719. https://doi.org/10.1177/0003122416655340

Kirkman, Maggie et al. 2009: Reasons women give for abortion: A review of the literature. In: Archives of Women's Mental Health 12,6: 365-378. https://doi.org/10.1007/s00737-009-0084-3 
Lauzon, Pierre et al. 2000: Emotional distress among couples involved in first-trimester induced abortion. In: Canadian Family Physician 46,10: 2033-2040.

Lillard, Lee A.; Waite, Linda J. 1993: A joint model of marital childbearing and marital disruption. In: Demography 30,4: 653-681. https://doi.org/10.2307/2061812

Major, Brenda et al. 2009: Abortion and mental health. Evaluating the evidence. In: American Psychologist 64,9: 863-890. https://doi.org/10.1037/a0017497

Mauldon, Jane; Foster, Diana Greene; Roberts, Sarah C. M. 2015: Effect of abortion vs. carrying to term on a woman's relationship with the man involved in the pregnancy. In: Perspectives on Sexual and Reproductive Health 47,1: 11-18. https://doi.org/10.1363/47e2315

Mclntyre, Marjorie; Anderson, Beverly; McDonald, Carol 2001: The intersection of relational and cultural narratives: Women's abortion experiences. In: Canadian Journal of Nursing Research 33,3: 47-62.

Meyer, Dixie et al. 2016: The possible trajectory of relationship satisfaction across the longevity of a romantic partnership: Is there a golden age of parenting? In: The Family Journal 24,4: 344-350. https://doi.org/10.1177/1066480716670141

Miller, Warren B. 1992: An empirical study of the psychological antecedents and consequences of induced abortion. In: Journal of Social Issues 48,3: 67-93. https://doi.org/10.1111/j.1540-4560.1992.tb00898.x

Miller, Warren B.; Pasta, David J.; Dean, Catherine L. 1998: Testing the model of the psychological consequences of abortion. In: Beckman, Linda J.; Harvey, S. Marie (Eds.): The New Civil War: The Psychology, Culture, and Politics of Abortion. Washington, DC: American Psychological Association: 235 267. https://doi.org/10.1037/10302-010

Philipps, Abimbola et al. 2015: Quality of spousal relationship on procurement of abortion in peri-urban Nigeria. In: African Journal of Reproductive Health 19,4: 14-22.

Poortman, Anne-Rigt; Lyngstad, Torkild Hovde 2007: Dissolution risks in first and higher order marital and cohabiting unions. In: Social Science Research 36,4: 1431-1446. https://doi.org/10.1016/j.ssresearch.2007.02.005

Randall, Ashley K.; Bodenmann, Guy 2009: The role of stress on close relationships and marital satisfaction. In: Clinical Psychology Review 29,2: 105-115. https://doi.org/10.1016/j.cpr.2008.10.004

Rossier, Clémentine et al. 2007: Modelling the process leading to abortion: An application to French survey data. In: Studies in Family Planning 38,3: 163-172. https://doi.org/10.1111/j.1728-4465.2007.00128.x

Schmaling, Karen B.; Goldman Sher, Tamara 2000: The Psychology of Couples and Illness: Theory, Research, and Practice. Washington, DC: American Psychological Association. https://doi.org/10.1037/10360-000

Sihvo, Sinikka et al. 2003: Women's life cycle and abortion decision in unintended pregnancies. In: Journal of Epidemiology and Community Health 57,8: 601-605. https://doi.org/10.1136/jech.57.8.601

Singer, Judith D.; Willett, John B. 1993: It's about time: Using discrete-time survival analysis to study duration and the timing of events. In: Journal of Educational Statistics 18,2: 155-195. https://doi.org/10.3102/10769986018002155

Skjeldestad, Finn Egil et al. 1994: Induced abortion. Effects of marital status, age and parity on choice of pregnancy termination. In: Acta Obstetrica et Gynecologica Scandinavica 73,3: 255-260. https://doi.org/10.3109/00016349409023450

Skolnick, Arlene S. 1986: The Psychology of Human Development. San Diego: Harcourt Brace Jovanovich. 
Torres, Aida; Forrest, Jacqueline 1988: Why do women have abortions? In: Family Planning Perspectives 20,4: 169-176. https://doi.org/10.2307/2135792

Väisänen, Heini 2015: The association between education and induced abortion for three cohorts of adults in Finland. In: Population Studies 69,3: 373-388. https://doi.org/10.1080/00324728.2015.1083608

Väisänen, Heini 2017: The timing of abortions, births, and union dissolutions in Finland. In: Demographic Research 37,28: 889-916. https://doi.org/10.4054/DemRes.2017.37.28

Van Damme, Maike; Dykstra, Pearl 2018: Spousal resources and relationship quality in eight European countries. In: Community, Work \& Family 21,5: 541-563. https://doi.org/10.1080/13668803.2018.1526776

Van Damme, Maike 2020: The negative female educational gradient of union dissolution: towards an explanation in six European Countries. In: Mortelmans, Dimitri (Ed.): Divorce in Europe. European Studies of Population, Vol 21. Cham: Springer. https://doi.org/10.1007/978-3-030-25838-2_5

Wheaton, Blair 1996: The domains and boundaries of stress concepts. In: Kaplan, Howard B. (Ed.): Psychosocial Stress: Perspectives on Structure, Theory, Life-Course, and Methods. San Diego: Academic Press: 29-70.

Wiik, Kenneth Aarskaug; Keizer, Renske; Lappegard, Trude 2012: Relationship quality and cohabiting unions across Europe. In: Journal of Marriage and Family 74,3: 389398. https://doi.org/10.1111/j.1741-3737.2012.00967.x

Wooldridge, Jeffrey M. 2010: Econometric Analysis of Cross Section and Panel Data. Cambridge, MA: MIT Press.

Kristin Hajek ( $\triangle)$. LMU Munich, Department of Sociology. Munich, Germany. E-mail: Kristin.Hajek@soziologie.uni-muenchen.de URL: https://www.en.Is3.soziologie.uni-muenchen.de/staff/academic_staff/hajek kristin/index.html 


\section{Appendix}

Tab. A1: Summary of logistic regression analyses estimating the likelihood of having an abortion versus having an unexpected/unwanted birth

\begin{tabular}{llc}
\hline Variable & \multicolumn{2}{c}{ Model 1} \\
& A.M.E. & S.E. \\
\hline Relationship satisfaction (scale: 0-10) & -0.013 & $(0.009)$ \\
Relationship duration in years & 0.006 & $(0.016)$ \\
Relationship duration in years squared & 0.000 & $(0.001)$ \\
Number of living children (ref.: no children) & & \\
$\quad$ child & 0.120 & $(0.065)$ \\
2 children & 0.076 & $(0.077)$ \\
3 or more children & 0.117 & $(0.088)$ \\
Relationship institutionalisation (ref.: married) & & \\
$\quad$ Cohabiting, unmarried & 0.051 & $(0.062)$ \\
$\quad$ Non-cohabiting & 0.110 & $(0.077)$ \\
Female partner's age at start of relationship & 0.005 & $(0.006)$ \\
Female partner's education level (ref. no degree/currently enrolled) & & \\
$\quad$ Lower secondary education & -0.040 & $(0.085)$ \\
$\quad$ Higher secondary education & -0.115 & $(0.079)$ \\
$\quad$ Post-secondary/tertiary education & $-0.206 *$ & $(0.090)$ \\
Male partner's employment status (ref.: part-time/unemployed) & & \\
$\quad$ Full-time & 0.038 & $(0.059)$ \\
Self-employed & 0.075 & $(0.092)$ \\
Main respondent female (ref. main respondent male) & -0.062 & $(0.046)$ \\
\hline Pseudo R & & \\
N (observations) & 0.026 & \\
N (couples) & 533 & \\
\hline & 475 & \\
\hline
\end{tabular}

Notes: ${ }^{*} \mathrm{p}<.05,{ }^{*} \mathrm{p}<.01,{ }^{*} * \mathrm{p}<.001$

Average marginal effects with cluster-robust standard errors in parentheses. Variables were measured in the wave before an abortion/unexpected birth was reported

Source: Own calculations based on pairfam waves 1-11, Release 11.0 
Tab. A2: Summary of discrete-time event history models estimating the likelihood of union dissolution

\begin{tabular}{|c|c|c|c|c|}
\hline \multirow[t]{2}{*}{ Variable } & \multicolumn{2}{|c|}{ Model 2} & \multicolumn{2}{|c|}{ Model 3} \\
\hline & A.M.E. & S.E. & A.M.E. & S.E. \\
\hline \multicolumn{5}{|l|}{ Abortion } \\
\hline In the wave of abortion & -0.007 & $(0.015)$ & -0.015 & $(0.014)$ \\
\hline One wave after abortion & 0.026 & $(0.017)$ & 0.016 & (0.016) \\
\hline Two waves after abortion & 0.039 & $(0.022)$ & 0.023 & (0.020) \\
\hline Three or more waves after abortion & 0.025 & $(0.014)$ & 0.018 & (0.013) \\
\hline \multicolumn{5}{|l|}{ Unexpected childbirth } \\
\hline In the wave of unexpected childbirth & $-0.071 * * *$ & $(0.011)$ & $-0.071 * * *$ & $(0.010)$ \\
\hline One wave after unexpected childbirth & $-0.051 * *$ & $(0.017)$ & $-0.051 * *$ & $(0.016)$ \\
\hline Two waves after unexpected childbirth & 0.008 & $(0.024)$ & -0.000 & $(0.022)$ \\
\hline $\begin{array}{l}\text { Three or more waves after unexpected } \\
\text { childbirth }\end{array}$ & 0.014 & $(0.018)$ & 0.012 & $(0.017)$ \\
\hline Relationship satisfaction (scale: $0-10$ ) & - & - & $-0.015^{* * *}$ & $(0.001)$ \\
\hline Relationship duration in years & $-0.021 * * *$ & $(0.001)$ & $-0.023 * * *$ & $(0.001)$ \\
\hline Relationship duration in years squared & $0.001 * * *$ & $(0.000)$ & $0.001 * * *$ & $(0.000)$ \\
\hline \multicolumn{5}{|l|}{ Number of living children (ref.: no children) } \\
\hline 1 child & 0.001 & $(0.005)$ & -0.004 & (0.005) \\
\hline 2 children & 0.009 & $(0.006)$ & 0.005 & (0.006) \\
\hline 3 or more children & 0.009 & $(0.008)$ & 0.005 & $(0.008)$ \\
\hline \multicolumn{5}{|l|}{ Relationship institutionalisation (ref.: married) } \\
\hline Cohabiting, unmarried & $0.031 * * *$ & $(0.004)$ & $0.027 * * *$ & $(0.004)$ \\
\hline Non-cohabiting & $0.100 * * *$ & $(0.006)$ & $0.091 * * *$ & (0.006) \\
\hline Female partner's age at start of relationship & $-0.002 * * *$ & $(0.000)$ & $-0.003 * * *$ & $(0.000)$ \\
\hline \multicolumn{5}{|c|}{ Female partner's education level (ref. no degree/currently enrolled) } \\
\hline Lower secondary education & 0.009 & $(0.006)$ & 0.004 & (0.006) \\
\hline Higher secondary education & $-0.010^{*}$ & $(0.004)$ & $-0.013^{* *}$ & (0.004) \\
\hline Post-secondary/tertiary education & $-0.030 * * *$ & $(0.005)$ & $-0.030 * * *$ & (0.005) \\
\hline \multicolumn{5}{|c|}{ Male partner's employment status (ref.: part-time/unemployed) } \\
\hline Full-time & $-0.024^{* * *}$ & $(0.003)$ & $-0.024 * * *$ & (0.003) \\
\hline Self-employed & -0.012 & $(0.007)$ & $-0.014^{*}$ & $(0.007)$ \\
\hline $\begin{array}{l}\text { Main respondent female } \\
\text { (ref. main respondent male) }\end{array}$ & 0.002 & $(0.003)$ & 0.001 & (0.003) \\
\hline Pseudo $\mathrm{R}^{2}$ & 0.242 & & 0.265 & \\
\hline N (observations) & 40,810 & & 40,810 & \\
\hline $\mathrm{N}$ (couples) & 10,833 & & 10,833 & \\
\hline
\end{tabular}

Notes: ${ }^{*} \mathrm{p}<.05,{ }^{*} \mathrm{p}<.01,{ }^{* * *} \mathrm{p}<.001$

Average marginal effects with cluster-robust standard errors in parentheses. Control variables were measured in the wave before an abortion/unexpected birth/union dissolution was reported

Source: Own calculations based on pairfam waves 1-11, Release 11.0 
Tab. A3: Summary of linear regression models estimating relationship satisfaction

\begin{tabular}{|c|c|c|c|c|}
\hline \multirow[t]{2}{*}{ Variable } & \multicolumn{2}{|c|}{ Model 4} & \multicolumn{2}{|c|}{ Model 5} \\
\hline & POLS & S.E. & $\mathrm{FE}$ & S.E. \\
\hline \multicolumn{5}{|l|}{ Abortion } \\
\hline In the wave of abortion & $-0.687^{* *}$ & $(0.225)$ & $-0.339 *$ & $(0.173)$ \\
\hline One wave after abortion & $-0.531^{*}$ & $(0.236)$ & -0.038 & (0.205) \\
\hline Two waves after abortion & $-0.679 *$ & $(0.278)$ & -0.035 & $(0.241)$ \\
\hline Three or more waves after abortion & $-0.627^{*}$ & $(0.249)$ & -0.210 & $(0.237)$ \\
\hline \multicolumn{5}{|l|}{ Unexpected childbirth } \\
\hline In the wave of unexpected childbirth & -0.066 & $(0.130)$ & 0.085 & (0.135) \\
\hline One wave after unexpected childbirth & $-0.450^{*}$ & (0.183) & -0.168 & (0.184) \\
\hline Two waves after unexpected childbirth & $-0.530^{*}$ & $(0.230)$ & -0.247 & (0.223) \\
\hline $\begin{array}{l}\text { Three or more waves after unexpected } \\
\text { childbirth }\end{array}$ & -0.311 & $(0.173)$ & -0.038 & $(0.181)$ \\
\hline Relationship duration in years & $-0.031 * *$ & $(0.011)$ & $-0.072^{* * *}$ & $(0.013)$ \\
\hline Relationship duration in years squared & $0.001 *$ & $(0.000)$ & $0.001 * *$ & $(0.000)$ \\
\hline \multicolumn{5}{|l|}{ Number of living children (ref.: no children) } \\
\hline 1 child & $-0.482^{* * *}$ & $(0.057)$ & $-0.314 * * *$ & $(0.062)$ \\
\hline 2 children & $-0.558 * * *$ & $(0.061)$ & $-0.468 * * *$ & (0.082) \\
\hline 3 or more children & $-0.513^{* * *}$ & $(0.080)$ & $-0.568 * * *$ & (0.119) \\
\hline \multicolumn{5}{|c|}{ Relationship institutionalisation (ref.: married) } \\
\hline Cohabiting, unmarried & $-0.354 * * *$ & $(0.057)$ & 0.048 & (0.057) \\
\hline Non-cohabiting & $-0.475 * * *$ & $(0.073)$ & 0.098 & $(0.074)$ \\
\hline \multicolumn{5}{|c|}{ Female partner's education level (ref. no degree/currently enrolled) } \\
\hline Lower secondary education & -0.207 & $(0.109)$ & 0.211 & $(0.156)$ \\
\hline Higher secondary education & $-0.323^{* * *}$ & $(0.061)$ & 0.069 & (0.059) \\
\hline Post-secondary/tertiary education & $-0.175^{* *}$ & $(0.066)$ & -0.094 & (0.077) \\
\hline \multicolumn{5}{|c|}{ Male partner's employment status (ref.: part-time/unemployed) } \\
\hline Full-time & 0.017 & $(0.048)$ & -0.020 & $(0.043)$ \\
\hline Self-employed & -0.067 & $(0.079)$ & -0.050 & (0.081) \\
\hline$R^{2}$ & 0.020 & & & \\
\hline $\mathrm{R}^{2}$ (within) & & & 0.013 & \\
\hline N (observations) & 32,683 & & 32,683 & \\
\hline $\mathrm{N}$ (couples) & 5,901 & & 5,901 & \\
\hline
\end{tabular}

Notes: ${ }^{*} p<.05,{ }^{*} p<.01,{ }^{* * *} p<.001$

Coefficients of pooled OLS (POLS) and fixed effects (FE) regression models with clusterrobust standard errors in parentheses. Control variables were measured in the wave before an abortion/relationship satisfaction was reported

Source: Own calculations based on pairfam waves 1-11, Release 11.0 


\section{Comparative Population Studies}

WWW.comparativepopulationstudies.de

ISSN: 1869-8980 (Print) - 1869-8999 (Internet)

\section{Published by}

Prof. Dr. Norbert F. Schneider

Federal Institute for Population Research D-65180 Wiesbaden / Germany

\section{(c) BY-SA}

2021

\section{Managing Editor}

Prof. Dr. Johannes Huinink

Dr. Katrin Schiefer

\section{Editorial Assistant}

Beatriz Feiler-Fuchs

Wiebke Hamann

\section{Layout}

Beatriz Feiler-Fuchs

E-mail:cpos@bib.bund.de

\section{Scientific Advisory Board}

Karsten Hank (Cologne)

Michaela Kreyenfeld (Berlin)

Marc Luy (Vienna)

Natalie Nitsche (Rostock)

Zsolt Spéder (Budapest)

Rainer Wehrhahn (Kiel)

\section{Board of Reviewers}

Bruno Arpino (Barcelona)

Kieron Barclay (Rostock)

Laura Bernardi (Lausanne)

Gabriele Doblhammer (Rostock)

Anette Eva Fasang (Berlin)

Michael Feldhaus (Oldenburg)

Tomas Frejka (Sanibel)

Alexia Fürnkranz-Prskawetz (Vienna)

Birgit Glorius (Chemnitz)

Fanny Janssen (Groningen)

Frank Kalter (Mannheim)

Stefanie Kley (Hamburg)

Bernhard Köppen (Koblenz)

Anne-Kristin Kuhnt (Duisburg)

Hill Kulu (St Andrews)

Nadja Milewski (Wiesbaden)

Roland Rau (Rostock)

Thorsten Schneider (Leipzig)

Tomas Sobotka (Vienna)

Jeroen J. A. Spijker (Barcelona)

Heike Trappe (Rostock)

Helga de Valk (The Hague)

Sergi Vidal (Barcelona)

Michael Wagner (Cologne) 